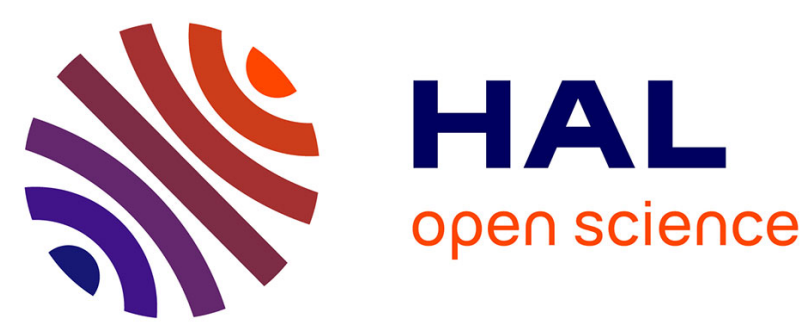

\title{
EnhanceMicroalgae: An European Interregional Project Stimulating Research, Innovation, Industrial Development and Transnational Cooperation within the Atlantic Area Microalgae Sector
}

Judith Rumin, Joana Martins, Jose Cruz, Vitor Vasconcelos, Claudio Fuentes Grünewald, Kevin J. Flynn, Alejandra Sabin, Maria Paredes, Enma Conde, Jose Vilarino, et al.

\section{- To cite this version:}

Judith Rumin, Joana Martins, Jose Cruz, Vitor Vasconcelos, Claudio Fuentes Grünewald, et al.. EnhanceMicroalgae: An European Interregional Project Stimulating Research, Innovation, Industrial Development and Transnational Cooperation within the Atlantic Area Microalgae Sector. Journal of Oceanography and Marine Research, 2018, 6 (3), pp.1000182. 10.4172/2572-3103.1000182 . hal01956157

\section{HAL Id: hal-01956157}

https://hal-univ-rochelle.archives-ouvertes.fr/hal-01956157

Submitted on 3 Jan 2019

HAL is a multi-disciplinary open access archive for the deposit and dissemination of scientific research documents, whether they are published or not. The documents may come from teaching and research institutions in France or abroad, or from public or private research centers.
L'archive ouverte pluridisciplinaire $\mathbf{H A L}$, est destinée au dépôt et à la diffusion de documents scientifiques de niveau recherche, publiés ou non, émanant des établissements d'enseignement et de recherche français ou étrangers, des laboratoires publics ou privés. 


\title{
EnhanceMicroalgae: An European Interregional Project Stimulating Research, Innovation, Industrial Development and Transnational Cooperation within the Atlantic Area Microalgae Sector
}

Judith Rumin', Joana Martins ${ }^{2,3}$, Jose Cruz ${ }^{2,3}$, Vitor Vasconcelos ${ }^{2,3}$, Claudio Fuentes Grünewald ${ }^{4}, K_{\text {Kevin Flynn }}^{4}$, Alejandra Sabin $^{5}$, Maria Paredes $^{5}$, Enma Conde ${ }^{6}$, Jose Vilarino ${ }^{6}$, Martina Ferreira ${ }^{7}$, Federica Farabegoli ${ }^{7}$, Paula Fajardo ${ }^{7}$, Maria-José Chapela ${ }^{7}$ and Laurent Picot ${ }^{1 *}$

${ }^{1}$ UMRi CNRS, LIENSs University of La Rochelle, 17042 La Rochelle, France

${ }^{2}$ Faculty of Sciences, University of Porto, Rua do Campo Alegre, Porto, 4169-007, Portugal

${ }^{3}$ CIIMAR Interdisciplinary Center of Marine and Environmental Research, University of Porto, Terminal de Cruzeiros do Porto de Leixões, Avenida General Norton de Matos, S/N, 450-208, Matosinhos, Portugal

${ }^{4}$ Department of Biosciences, College of Science, Swansea University, Prifysgol Abertawe SA28PP, Wales, UK

${ }^{5}$ METMED Facultade de Ciencias, University of A Coruña, 15071 A Coruna, Spain

${ }^{6}$ Glecex, Edificio CEI, San Cibrao das Viñas, 32900, Ourense, Spain

${ }^{7}$ ANFACO-CECOPESCA, Estrada Colexio Universitario, 16, 36310, Pontevedra, Spain

\begin{abstract}
Although microalgae comprise an estimated number of 30,000 to $1,000,000$ species, few are grown commercially. This natural resource offers great industrial potential, exploiting its chemical composition or biotechnological potential through growth manipulations. At the same time, this complexity can overwhelm enterprises entering this sector due to the great number of variables affecting economic and environmental viability. The strategic objective of the INTERREG Atlantic Area EnhanceMicroalgae project EAPA 338/2016 (2017-2020) is to create a network of European scientific and industrial partners to stimulate innovation and competitiveness of the European Atlantic Area in high technology sectors related to microalgae (in particular pharma, food and nutraceuticals). The work program includes an in-depth review of the existing Atlantic Area microalgae sector (strengths and weaknesses, level of expertise, industrial development opportunities, regulatory and legal frameworks), innovative research activities and innovation transfer from laboratories/ research platforms to the industrial sector to promote the emergence of new products, services and processes. The EnhanceMicroalgae consortium offers a wide range of skills and interests, with strong track records for research, production and exploitation of microalgae throughout the Atlantic Area.
\end{abstract}

Keywords: Biotechnology; High-added value industrial opportunities; Innovation and competitiveness; Innovation transfer; INTERREG; Market; Microalgae; Phytoplankton; SMEs; Transnational cooperation

\section{Introduction}

The European Atlantic area has a high potential for research, innovation and industrial development in the sector of microalgae production and biotechnology. Bringing together a critical number of expert researchers, the region also benefits from biotech companies and technological platforms producing sustainable and high-quality microalgae and working in international research networks. In view of the biotechnological potential of microalgae to provide high-added value natural molecules of interest for feed, food, nutraceutical, pharma and cosmetic applications, there is a significant need to transfer the latest research and technological developments to the business sector, thereby facilitating production of large biomass volumes and optimizing production processes with respect to their different final products.

Based on these considerations, the EnhanceMicroalgae project was funded to launch on the $1^{\text {st }}$ of November 2017 and run until the end of October 2020. Bringing together 13 academic and private partners from 5 countries bordering the Atlantic Ocean (Figure 1), this transnational project entitled as "High added-value industrial opportunities for microalgae in the Atlantic Area - EnhanceMicroalgae", obtained a €2.45 Million budget funded by the INTERREG Atlantic Area - European program to fulfill the following main objectives:

1. Undertake a comprehensive analysis of skills, skill gaps and opportunities in the microalgae sector in the European Atlantic area (industrial/academic).

2. Develop case studies, supported by Decision Support Tools (DST), to increase economic performance and competitiveness with transfer of know-how from academic and technological centers to SMEs.

3. Analyze critical factors of operation from environmental and legal/legislative points of view.

4. Incorporate nanotechnology/new technologies (emerging and/ or transferred from other sectors) to microalgae sector.

5. Encourage the creation of spin offs and self-employment.

In order to properly address and integrate across these strategic objectives, 8 work packages (WPs) engage researchers and companies in a dynamic of expertise, communication, training sessions and

*Corresponding author: Dr. Laurent Picot, Département of Biochemistry, UMR CNRS 7266 LIENSs University of La Rochelle, 17042 La Rochelle, France, Tel: +33(0)546458220; E-mail: laurent.picot@univ-Ir.fr

Received October 31, 2018; Accepted November 14, 2018; Published November 21, 2018

Citation: Rumin J, Martins J, Cruz J, Vasconcelos V, Grünewald CF, et al. (2018) EnhanceMicroalgae: An European Interregional Project Stimulating Research Innovation, Industrial Development and Transnational Cooperation within the Atlantic Area Microalgae Sector. J Oceanogr Mar Res 6: 182. doi: 10.4172/25723103.1000182

Copyright: (c) 2018 Rumin J, et al. This is an open-access article distributed unde the terms of the Creative Commons Attribution License, which permits unrestricted use, distribution, and reproduction in any medium, provided the original author and source are credited. 
Citation: Rumin J, Martins J, Cruz J, Vasconcelos V, Grünewald CF, et al. (2018) EnhanceMicroalgae: An European Interregional Project Stimulating Research, Innovation, Industrial Development and Transnational Cooperation within the Atlantic Area Microalgae Sector. J Oceanogr Mar Res 6: 182. doi: 10.4172/2572-3103.1000182

Page 2 of 3

dissemination. Every partner in the project is involved in all WPs, bringing specific national expertise and also benefiting from an overview of the sector at the European level.

WP1 "Project coordination", led by the National AssociationNational Technical Centre for the Conservation of Fishery Products (ANFACO-CECOPESCA) located in Vigo, Spain, coordinates the whole project in line with the INTERREG Atlantic Area European program.

WP2 "Communication", led by University of Manchester, UK, organizes the communication and dissemination activities to give the project a high visibility for scientists, industrials, stakeholders and target groups (e.g. communication and demonstration for the general public). All public data obtained during the project will be disseminated to the scientific community, stakeholders and public via conferences, dissemination and technology transfer sessions, leaflets, downloadable documents and on-line databases accessible on the website of the project: www.enhancemicroalgae.eu

WP3 "Capitalization", led by the International Iberian Nanotechnology Laboratory (INL), Portugal, exploits the knowledge and innovations arising from the project, to support spin-off and startup creation, foster skilled employment in the microalgae sector and warrant the sustainability of the transference programs.

WP4 "Gaps and technical barriers identification", led by University of La Rochelle, France, identifies scientific, technological, legislative and social barriers limiting the industrial development of the microalgae sector as well as opportunities for the microalgae sector development. This involves the creation of a public database of stakeholders, SWOT analysis of the sector, bibliographic/bibliometric and patent analysis of the sector, survey and DELPHI study with experts, and redaction of a guidebook presenting strategies and guidelines to improve the microalgae sector.

WP5 "Market research: opportunities and application", led by La Coruña University, Spain, undertakes market analyses to guide opportunities for the microalgae market development. Running in parallel with WP4, where gaps and barriers are identified, it evaluates the past and current microalgae-based products markets to seek trends into the future, explore market opportunities for cosmetic ingredients, nutraceutical extracts, phytochemical production, animal and human nutrition and identifies best practice configurations of business strategies/consortia. WP5 objectives will be achieved using state-of-the-art tools for creative market analysis, common among technological startups, to obtain work plans aligned with the language of entrepreneurs and investors. Another important aspect of WP5 is to evaluate success cases that are currently operating in other regions of the world, possible transfer and adaptability of those models in the Atlantic area.

WP6 "Legislation surveillance and environmental concern", led by Faculdade de Ciências da Universidade do Porto (FCUP)/ Interdisciplinary Centre of Marine and Environmental Research (CIIMAR), Portugal, performs advanced analyses of the legislation for food and feed uses of microalgae and identifies potential environmental impacts of microalgae exploitation in the fields defined in Annex I of
Directive 2001/42/EEC (biodiversity, population, human health, fauna, flora, soil, water, air, climatic factors, material assets, cultural heritage and landscape). These analyses will identify regulatory frameworks governing microalgae research, production and commercialization, their current limitations and possible evolutions with special attention to issues and impacts related to the application of the Nagoya Protocol and to the importation of biomass and microalgae-based products from outside Europe. A review of regional regulations that can vary between and within countries will be performed; this will help to harmonize European legislation related to uses, safety and environmental impacts of the microalgae business.

WP7 "Knowledge research and development towards value applications", led by Swansea University, UK, provides private companies with protocols for reliable bulk growth of microalgae of contrasting types to provide protein-rich or carbohydrate/lipid rich biomass. This is required to support food industries and also production of fine chemicals. All partners are involved in the activity according to their experience, including selection, growth and screening of novel microalgae species, optimization of biomass production, harvesting and fractionation, fine chemicals and metabolites characterization, encapsulation, for pharma, food, cosmetic and aquaculture applications. Documentation and dissemination actions for industrials will guide the selection of strains, culture and processes to increase the business potential for target applications. Companies will be offered support, both for developing new products and for obtaining multi-products based on the same microalgal culture, through the implementation of a DST; a combination of technical and financial modelling.

WP8 "Knowledge transfer activities", led by ANFACOCECOPESCA, Vigo, Spain, includes the development of a knowledge transfer portfolio of the project, organization of short visits for internships and onsite training related with knowledge transfer, development of a fully functional Intellectual Property Right \& technology transfer data management system and virtual office, as well as organization of brokerage activities. The portfolio will facilitate the access to the technologies and resources available in the consortium in order to foster their commercial exploitation. An online open access marketplace will be created, for the exchange of ideas, knowledge, technologies and services and to foster the transfer of knowledge portfolio to the industrial sector, in order to boost business development.

Launched in November 2017, the EnhanceMicroalgae project will present its first results and public communications event in December 2018 during a 2 days' workshop in La Rochelle, France. The first day of the workshop will bring together scientists, private companies and invited European experts to share knowledge, experience and points of view and consider future actions for the Atlantic Area microalgae sector. We encourage all stakeholders involved in the development of the microalgae sector in the Atlantic area and interested to interact with the EnhanceMicroalgae consortium to contact the lead coordinator at uii@anfaco.es and consult the project website, to participate to the online survey, follow the project progress and access databases and downloadable documents (Figure 1). 
Citation: Rumin J, Martins J, Cruz J, Vasconcelos V, Grünewald CF, et al. (2018) EnhanceMicroalgae: An European Interregional Project Stimulating Research, Innovation, Industrial Development and Transnational Cooperation within the Atlantic Area Microalgae Sector. J Oceanogr Mar Res 6: 182. doi: 10.4172/2572-3103.1000182

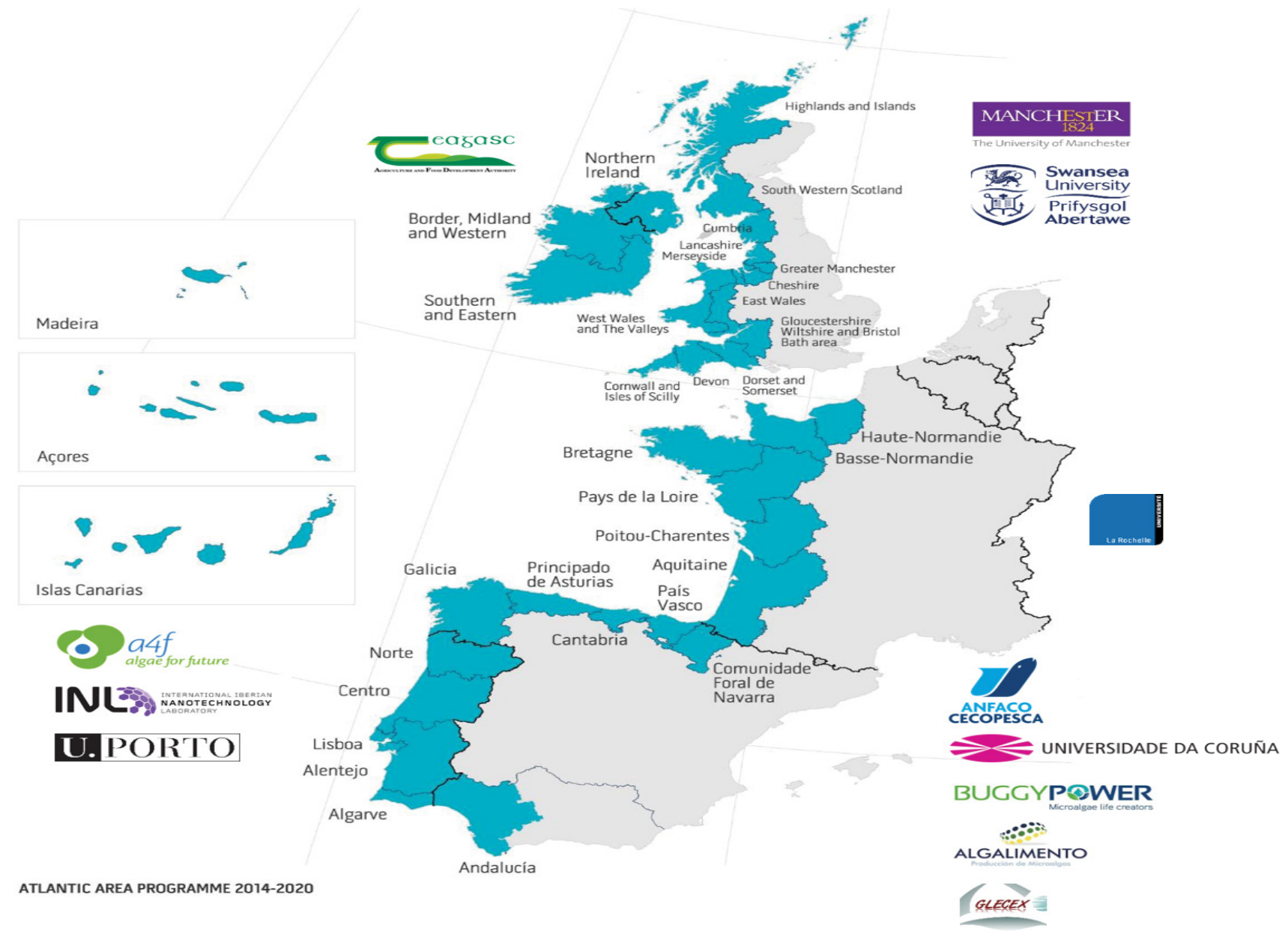

Figure 1: Map of the European Atlantic Area regions benefiting from the INTERREG Atlantic Area funding program and identification of the EnhanceMicroalgae partners. The region includes 36 coastline administrative regions from 5 countries (Portugal, Spain, France, UK, Ireland). The partnership includes the National Association-National Technical Centre for the Conservation of Fishery Products ANFACO-CECOPESCA (SP), La Coruña University (SP), Global and Ecofriendly Natural Extracts Glecex S.L. (SP), Algalimento S.L. (SP), Buggypower (SP), Hijos de Rivera S.A.U. (SP), University of Porto (PT), International Iberian Nanotechnology laboratory INL (PT), Algae for future S.A. (PT), University of La Rochelle (FR), Swansea University (UK), University of Manchester (UK) and Teagasc (IRE).

\section{Conflicts of Interest}

The authors declare no conflict of interest.

\section{Acknowledgement}

This work was financially supported by the INTERREG Atlantic Area European programme EnhanceMicroalgae project EAPA_338/2016. 